\title{
Chemical weather forecasting: a new concept of integrated modelling
}

\author{
A. Baklanov \\ Danish Meteorological Institute, Lyngbyvej 100, 2100 Copenhagen, Denmark
}

Received: 23 December 2009 - Revised: 14 March 2010 - Accepted: 24 March 2010 - Published: 26 March 2010

\begin{abstract}
During the last decade a new field of atmospheric modelling - the chemical weather forecasting $(\mathrm{CWF})$ - is quickly developing and growing. However, in the most of the current studies and publications, this field is considered in a simplified concept of the off-line running chemical transport models with operational numerical weather prediction (NWP) data as a driver. A new concept and methodology considering the chemical weather as two-way interacting meteorological weather and chemical composition of the atmosphere is suggested and discussed. The on-line integration of mesometeorological models and atmospheric aerosol and chemical transport models gives a possibility to utilize all meteorological 3-D fields in the chemical transport model at each time step and to consider feedbacks of air pollution (e.g. urban aerosols) on meteorological processes/climate forcing and then on the atmospheric chemical composition. This very promising way for future atmospheric simulation systems (as a part of and a step to Earth System Modelling) will lead to a new generation of models for meteorological, environmental and chemical weather forecasting. The methodology how to realise the suggested integrated CWF concept is demonstrated on the example of the European EnviroHIRLAM integrated system. The importance of different feedback mechanisms for CWF is also discussed in the paper.
\end{abstract}

\section{Introduction}

During the last decade a new field of atmospheric modelling - the chemical weather forecasting (CWF) - is quickly developing and growing (Lawrence et al., 2005). This was possible mostly due to the quickly growing supercomputer capability and operationally available high-resolution numerical weather prediction (NWP) data for atmospheric chemical transport models (ACTMs). However, in the most of the current systems, studies and publications this new direction is considered in a simplified concept. It includes only operational air quality forecast for the main pollutants significant for health effects and uses numerical ACTMs with operational NWP data as a driver (see e.g. the COST Action ES0602: Towards a European Network on Chemical Weather Forecasting and Information Systems, website: http://www.chemicalweather.eu/, leader Prof. J. Kukkonen).

Such an approach has limitations due to the off-line way of coupling the ACTMs with NWP or mesometeorological models (MMMs) (which are running fully independently and NWP does not get any benefits from the ACTM) without a

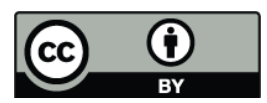

Correspondence to: A. Baklanov (alb@dmi.dk) possibility to consider any feedback mechanisms. Many experimental studies (Rosenfeld, 2000; Bellouin et al., 2005; Ramanathan and Carmichael, 2008) and numerical research simulations (Jacobson, 2002; Grell et al., 2004; Schulz et al., 2006) show that atmospheric processes (meteorological weather, including the precipitation, thunderstorms, radiation budget, cloud processes and planetary boundary-layer (PBL) structure) depend on concentrations of chemical components in the atmosphere.

Chemical species influencing weather and atmospheric processes include greenhouse gases which warm nearsurface air and aerosols such as sea salt, dust, primary and secondary particles of anthropogenic and natural origin. Some aerosol particle components (black carbon, iron, aluminium, polycyclic and nitrated aromatic compounds) warm the air by absorbing solar and thermal-infrared radiation, while others (water, sulphate, nitrate, most of organic compounds) cool the air by backscattering incident short-wave radiation to space. The aerosols, beside the above mentioned direct effect (via radiation), include many other different mechanisms of aerosol-chemistry-cloud-radiation-PBLemission interactions, in particular the semi-direct, first and second indirect effects. 
Therefore ACTMs have to be run together with NWP models on the same computational grid and with the same time step using online coupling and considering two-way interaction between the meteorological processes, from one side, and chemical transformation and aerosol dynamics, from the other side.

\section{Concept and methodology for integrated CWF modeling}

Proceeding from the above mentioned limitations, a new concept and methodology considering the chemical weather as two-way interacting physical and chemical weather is suggested. The CWF should include not only health-effecting pollutants (air quality components) but also green-house gases and aerosols effecting climate, meteorological processes, etc. Such a concept of CWF requests a strategy of a new generation integrated meteorology and ACT modelling systems for predicting atmospheric composition, meteorology and climate change. The on-line integration of meteorological or NWP models and atmospheric aerosol and chemical transport models gives a possibility to utilise all meteorological 3-D fields in ACTM at each time step and to consider feedbacks of atmospheric aerosols on meteorological processes and climate forcing, and further on the chemical composition (as a chain of dependent nonlinear processes). This promising way for future atmospheric simulation systems will lead to a new generation of integrated models for meteorological, environmental and chemical weather forecasting.

The current COST728 Action "Enhancing meso-scale meteorological modelling capabilities for air pollution and dispersion applications" (http://www.cost728.org, leader Prof. R. Sokhi) addresses key issues concerning the development of meso-scale models for atmospheric environmental problems and, in particular, it encourages the advancement of science in terms of integration methodologies and strategies in Europe. The final integration strategy will not be focused around any particular model, instead it will be possible to consider an open integrated system with a fixed architecture (module interface structure) and with a possibility of incorporating different ACTMs and MMMs/NWP models. Such a strategy may only be realised through jointly agreed specifications of module structure for easy-to-use interfacing and integration.

The overall aim of COST728 working group 2 (WG2), "Integrated systems of MMM and ACTM: strategy, interfaces and module unification", is to identify the requirements for the unification of MMM and ACTM modules and to propose recommendations for a European strategy for integrated meso-scale modelling capabilities. The first report of WG2 (COST-WMO, 2007) compiles the existing state-ofthe-art methodologies, approaches, models and practices for building integrated (offline and online) meso-scale systems in different, mostly European, countries. The report also includes an overview and a summary of the existing integrated models and their characteristics as they are presently used. The model contributions were compiled using COST member contributions, each focusing on national model systems.

The modern strategy for integrating MMMs and ACTMs is suggested to consider air quality modelling as a combination of (at least) the following factors: air pollution, regional/urban climate/meteorological conditions and population exposure. This combination is reasonable due to the following facts: meteorology is the main source of uncertainty in air pollution and emergency preparedness models; meteorological and pollution components have complex and combined effects on human health (e.g., the Paris deadly heat wave in July-August 2003 was caused by different combined risk factors: high temperature, ozone concentrations, etc.); pollutants, especially aerosols, influence climate forcing and meteorological events (radiation, precipitation, thunderstorms, etc.).

The integration/coupling of the NWP/MMM and ACT models can be realized by different ways using the online and offline modelling approaches. In more details the definition and specifics of the approaches, as well as the advantages and disadvantages of the online and offline modelling are described by Baklanov and Korsholm (2007) and in the COST-WMO report (2007). It can be realized using the following possible variants (see Fig. 1):

One-way integration (offline coupling):

1. MMM (or any other regional climate or NWP model) meteorological fields used to drive ACTM (this way is traditionally used by many air pollution modellers) $(\longleftarrow)$;

2. ACTM chemical composition fields as a driver for regional climate modelling or for NWP (e.g. for aerosol forcing on meteo-processes) $(-\rightarrow)$.

Two-way integration:

1. Driver and partial feedbacks, for ACTM or for NWP (data exchange via an interface with a limited time period: offline or online access coupling) $(\Leftarrow \Rightarrow)$;

2. ACTM built inside MMM or NWP model with full feedbacks included on each time step (online coupling) $(\Longleftrightarrow)$.

In this context, several levels of MMM and ACTM coupling/integration can be considered:

off-line:

- separate ACTMs driven by meteorological input data from meteo-preprocessors, measurements or diagnostic models, 


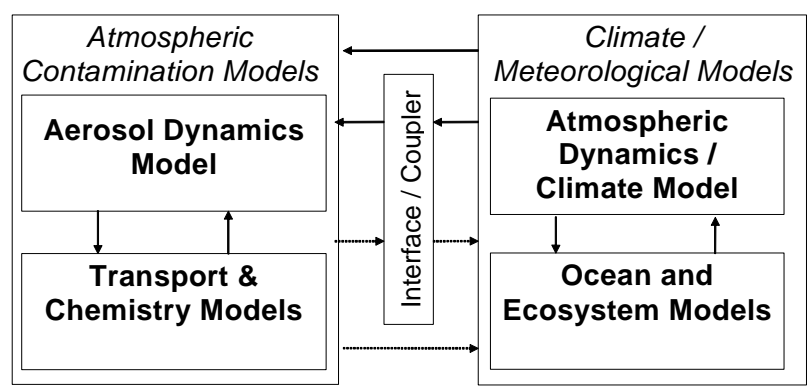

Figure 1. Schematic diagram of different approaches for the integration of meteorological/climate and atmospheric chemical transport models with one- or two-way interactions. Online coupling can be achieved through the use of various available coupling tools or through directly inlining the chemical and aerosol modules into the NWP models.

- separate ACTMs driven by analysed or forecasted meteorological data from NWP archives or datasets,

- separate ACTMs reading output-files from operational NWP models or specific MMMs at limited time intervals (e.g. 1, 3,6h).

on-line:

- on-line access models, when meteorological data are available at each time-step (possibly via a model interface as well),

- on-line integration of ACTM into MMM, where twoway feedbacks may be considered. We will use this definition for on-line coupled/integrated modelling.

The last level of the on-line integration with two-way feedbacks can consider the full chain of feedbacks and is recommended as the main strategy for integrated CWF models. These methodologies of the integrated CWF have been realised by several of the COST action partners such as the Danish Meteorological Institute (DMI), with the EnviroHIRLAM model (Baklanov et al., 2008a; Korsholm et al., 2008; Korsholm, 2009) and the COSMO consortium with the Lokal Modell (Vogel et al., 2006; Wolke et al., 2003), as well as the American WRF-Chem (Grell et al., 2004, 2005) integrated system. These model developments for chemical weather forecasting are an activity of increasing importance which is due to be supported by the ongoing COST action ES0602.
The Enviro-HIRLAM integrated system, recently developed by DMI and other collaborators ${ }^{1}$ (Chenevez et al., 2004; Baklanov et al., 2008a; Korsholm et al., 2008, Korsholm, 2009), is an online coupled model for research and forecasting of both meteorological and chemical weather. It includes two-way feedbacks between air-pollutants and meteorological processes. Atmospheric chemical transport equations are implemented inside the meteorological corner on each time step (Chenevez et al., 2004). To make the model suitable for CWF in urban areas, where most of the population is concentrated, the meteorological part is improved by the implementation of urban sublayer modules and parameterisations (Baklanov et al., 2008b). The aerosol module in Enviro-HIRLAM comprises a thermodynamic equilibrium model and the aerosol dynamics model CAC (Gross and Baklanov, 2004) based on the modal approach. Parameterisations of the aerosol feedback mechanisms in the EnviroHIRLAM model are described in Korsholm et al. (2008) and Korsholm (2009). Several chemical mechanisms can be chosen depending on the specific tasks.

Model validation and sensitivity tests of the on-line versus off-line integrated versions (Grell et al., 2004, 2005; Korsholm et al., 2009) show that the online coupling improves the modelling results. Grell et al. (2005) show improved predictions of average ozone concentrations when using the online version of WRF-Chem. Korsholm et al. (2009) using the online Enviro-HIRLAM for the ETEX-1 experiment release show that the off-line coupling interval increase leads to considerable error and a false peak (not found in the observations), which almost disappears in the online version that resolves meso-scale influences during plume development.

In the case study by Zhang (2008) it was shown that including only the direct aerosol effects leads to a temperature change about $0.2{ }^{\circ} \mathrm{C}$ and the water vapor mixing ratio increases more than $3 \%$ at/near surface. The effects of urban aerosols on the urban boundary layer height, can be of the same order of magnitude as the effects of the urban heat island ( $\Delta h$ is up to $100-200 \mathrm{~m}$ for stable boundary layer) (Baklanov et al., 2008a). Korsholm et al. (2009) show that aerosol feedbacks through the second indirect effect induce considerable changes in meteorological fields and large changes in chemical composition, in particular $\mathrm{NO}_{2}$, in a case of convective cloud cover and little precipitation.

\footnotetext{
${ }^{1}$ At the current stage the Enviro-HIRLAM model is used as the baseline system for the HIRLAM chemical branch, and additionally to the HIRLAM community the following groups join the development team: University of Copenhagen, Tartu University (Estonia), Russian State Hydro-Meteorological University, Bilbao University (Spain), Odessa State Environmental University (Ukraine), etc.
} 


\section{Discussion and conclusions}

The new concept and methodology considering the chemical weather as two-way interacting meteorological weather and chemical composition of the atmosphere is suggested for future chemical weather forecasting systems.

These on-line coupled model developments will lead to a new generation of integrated models not only for the chemical weather forecasting, but also for improved meteorological weather forecasting (e.g., in urban areas, severe weather events, fog and visibility, UV-radiation and solar energy, etc.), bio-meteorological forecasting, climate change modelling, air quality analysis and mitigations, long-term assessment chemical composition.

Main advantages of the on-line modelling approach include: (i) Only one grid for MMM and ACTM, no interpolation in space and time, (ii) Physical parameterizations and numerical schemes are the same, no inconsistencies; (iii) All 3-D meteorological variables are available at the right time at each time step; (iv) No restriction in variability of meteorological fields; (v) Possibility to consider two-way feedback mechanisms; (vi) No need for meteo- pre/post-processors.

However, for specific tasks the off-line approach can also be useful and includes the following advantages in separate cases, e.g. for risk assessments: (i) Possibility of independent parameterizations; (ii) More suitable for ensemble activities; (iii) Easier to use for the inverse modelling and adjoint problem; (iv) Independence of atmospheric pollution model runs on meteorological model computations; (v) More flexible grid construction and generation for ACTMs, (vi) Suitable for emission scenarios analysis and air quality management.

The COST-WMO (2007) and further COST-NetFAM (2008) overviews show a quite surprising number of online coupled MMM and ACTM model systems already being used in Europe. However, many of the on-line coupled models are not built for the mesometeorological scale, and they (e.g. GME, ECMWF GEMS, MESSy) are global-scale modelling systems and first of all designed for climate change modelling. Besides, at the current stage most of the online coupled models do not consider feedback mechanisms or include only direct effects of aerosols on meteorological processes (like COSMO LM-ART and MCCM). Only two meso-scale on-line integrated modelling systems (WRFChem and Enviro-HIRLAM) consider feedbacks with indirect effects of aerosols.

It is necessary to highlight that the interactions of aerosols and other chemical species with meteorological processes have many different pathways and they have to be prioritised and considered in on-line coupled modelling systems for CWF. Further sensitivity studies are needed to understand the relative importance of different feedback mechanisms for different species, scales and conditions relevant to air quality and meteorology interactions. A concerted action to mobilise and coordinate European research in this area is needed.
Acknowledgements. This study was supported by the COST Actions 728 and ES0602, NetFAM, EC FP7 Project MEGAPOLI and the Copenhagen Global Change Initiative (COGCI). The author is grateful to a number of COST728, FUMAPEX, EnviroHIRLAM, MEGAPOLI and DMI colleagues, who participated in the above-mentioned projects, for productive collaboration and discussions. Especial thanks are to my former PhD student Ulrik Korsholm (DMI) who realised most of the Enviro-HIRLAM model coding, simulation runs and studies of the aerosol indirect effects.

Edited by: M. Piringer

Reviewed by: two anonymous referees

\section{References}

Baklanov, A. and Korsholm, U.: On-line integrated meteorological and chemical transport modelling: advantages and prospective, in: ITM 2007: 29th NATO/SPS International Technical Meeting on Air Pollution. Modelling and its Application, 24-28.09.2007, University of Aveiro, Portugal, 21-34, 2007.

Baklanov, A., Korsholm, U., Mahura, A., Petersen, C., and Gross, A.: ENVIRO-HIRLAM: on-line coupled modelling of urban meteorology and air pollution, Adv. Sci. Res., 2, 41-46, 2008a.

Baklanov, A., Mestayer, P. G., Clappier, A., Zilitinkevich, S., Joffre, S., Mahura, A., and Nielsen, N. W.: Towards improving the simulation of meteorological fields in urban areas through updated/advanced surface fluxes description, Atmos. Chem. Phys., 8, 523-543, 2008b,

http://www.atmos-chem-phys.net/8/523/2008/.

Bellouin, N., Boucher, O., Haywood, J., and Reddy, M. S.: Global estimate of aerosol direct radiative forcing from satellite measurements, Nature, 438, 1138-1141, 2005.

Chenevez, J., Baklanov, A., and Sørensen, J. H.: Pollutant transport schemes integrated in a numerical weather prediction model: Model description and verification results, Meteorol. Appl., 11(3), 265-275, 2004.

COST-NetFAM: Integrated systems of meso-meteorological and chemical transport models, edited by: Baklanov, A., Mahura, A., and Sokhi, R., Materials of the COST-728/NetFAM workshop, DMI, Copenhagen, 21-23 May 2007, 183 pp., Springer (in press), available at: http://www.cost728.org, 2008.

COST-WMO: Overview of existing integrated (off-line and on-line) meso-scale systems in Europe, edited by: Baklanov, A., Fay, B., Kaminski, J., Sokhi, R., Joint Report of COST728 and GURME, May 2007, WMO-COST publication, GAW Report No. 177, WMO TD No. 1427, available at: http://www.cost728.org, 2007.

Grell, G. A., Knoche, R., Peckham, S. E., and McKeen, S.: Online versus offline air quality modeling on cloud-resolving scales, Geophys. Res. Lett., 31, L16117, doi:10.1029/2004GL020175, 2004.

Grell, G. A., Peckham, S. E., Schmitz, R., McKeen, S. A., Frost, G., Skamarock, W. C., and Eder, B.: Fully coupled "online" chemistry within the WRF model, Atmos. Environ., 39(37), 69576975, 2005.

Gross, A. and Baklanov, A.: Modelling the influence of dimethyl sulphide on the aerosol production in the marine boundary layer, Int. J. Environ. Pollut., 22, 51-71, 2004. 
Jacobson, M. Z.: Control of fossil-fuel particulate black carbon and organic matter, possibly the most effective method of slowing global warming, J. Geophys. Res., 107(D19), 4410, doi:10.1029/2001JD001376, 2002.

Korsholm, U.: Integrated modeling of aerosol indirect effects - development and application of a chemical weather model, $\mathrm{PhD}$ thesis University of Copenhagen, Niels Bohr Institute and Danish Meteorological Institute, Research department, http://www. dmi.dk/dmi/sr09-01.pdf, 2009.

Korsholm, U. S., Baklanov, A., Gross, A., Mahura, A., Sass, B. H., and Kaas, E.: Online coupled chemical weather forecasting based on HIRLAM - overview and prospective of EnviroHIRLAM, HIRLAM Newsletter, 54, 151-168, 2008.

Korsholm, U. S., Baklanov, A., Gross, A., and Sørensen, J. H.: On the importance of the meteorological coupling interval in dispersion modeling during ETEX-1, Atmos. Environ., 43(31), 48054810, 2009.

Lawrence, M. G., Hov, Ø., Backmann, M., Brandt, J., Elbern, H., Eskes, H., Feichter, H., and Takigawa, M.: The Chemical Weather. Environ. Chem., 2, 6-8, 2005.

Ramanathan, V. and Carmichael, G.: Global and regional climate changes due to black carbon, Nature Geosci., 1(4), 221-227, 2008 .
Rosenfeld, D.: Suppression of Rain and Snow by Urban and Industrial Air Pollution, Science, 287(5459), 1793-1796, 2000.

Schulz, M., Textor, C., Kinne, S., Balkanski, Y., Bauer, S., Berntsen, T., Berglen, T., Boucher, O., Dentener, F., Guibert, S., Isaksen, I. S. A., Iversen, T., Koch, D., Kirkevåg, A., Liu, X., Montanaro, V., Myhre, G., Penner, J. E., Pitari, G., Reddy, S., Seland,Ø., Stier, P., and Takemura, T.: Radiative forcing by aerosols as derived from the AeroCom present-day and pre-industrial simulations, Atmos. Chem. Phys., 6, 5225-5246, 2006, http://www.atmos-chem-phys.net/6/5225/2006/.

Vogel, B., Hoose, C., Vogel, H., and Kottmeier, Ch.: A model of dust transport applied to the Dead Sea area, Meteorol. Z., 14, 611-624, 2006.

Wolke, R., Hellmuth, O., Knoth, O., Schröder, W., Heinrich, B., and Renner, E.: The chemistry-transport modeling system LMMUSCAT: Description and CITYDELTA applications. Proceedings of the 26-th International Technical Meeting on Air Pollution and Its Application. Istanbul, May 2003, 369-379, 2003.

Zhang, Y.: Online-coupled meteorology and chemistry models: history, current status, and outlook, Atmos. Chem. Phys., 8, 28952932, 2008,

http://www.atmos-chem-phys.net/8/2895/2008/. 